\title{
The value of GeneXpert MTB/RIF in bronchoalveolar lavage fluid in the diagnosis of smear-negative pulmonary tuberculosis.
}

\author{
Yue-Ying Zhou, Ji-Chan Shi, Ning Pan, Zheng-Xing Wu, Ai-Qiong Cheng, \\ Yan-Hong Mei, Lian-Peng Wu and Xian-Gao Jiang \\ Department of Infectious Diseases, Wenzhou Central Hospital, Wenzhou, Zhejiang, \\ China.
}

Key words: bronchoalveolar lavage fluid; Xpert MTB/RIF; tuberculosis; Mycobacterium culture; rifampicin resistance.

\begin{abstract}
This study aims to evaluate the diagnostic value of Xpert MTB/ RIF assay in bronchoalveolar lavage fluid (BALF) in subjects with smear-negative pulmonary tuberculosis. From January 2019 to December 2019, 197 patients with suspected pulmonary tubereulosis were recruited, and bronchoalveolar lavage fluid was collected for acid-fast staining smear, liquid culture of Mycobacterium combined drug sensitivity and Xpert MTB/RIF detection. The sensitivity, specificity, positive predictive value and negative predictive value of Xpert MTB/RIF in bronchoalveolar lavage fluid (BALF) were calculated with smear-negative pulmonary tuberculosis as the reference standard. The consistency of xpert MTB/RIF in the diagnosis of rifampicin resistance was evaluated, with the results of Mycobacterium liquid culture drug sensitivity test and drug sensitivity test as the gold standards. The results showed that among 197 suspected tuberculosis patients, 55 patients were not diagnosed with tuberculosis and 142 patients were diagnosed with smear-negative pulmonary tuberculosis. One hundred and twenty three cases (86.62\%) were positive for Xpert MTB/ RIF in bronchoalveolar lavage fluid, 15 cases (10.56\%) were positive by acid-fast staining smear method, and 88 cases $(61.97 \%)$ were positive by the liquid culture method. The positive rate of Xpert MTB / RIF was 93.18\% (82 / 88), which was higher than that of $75.93 \%(41 / 54)$ of the negative BALF mycobacterium culture $(\chi 2=8.598, \mathrm{P}<0.01)$. The sensitivity and specificity of Xpert MTB/RIF for rifampicin resistance were $100.00 \%$ and $97.30 \%$, respectively. Therefore, the diagnostic value of Xpert MTB/RIF in bronchoalveolar lavage fluid for bacterialnegative pulmonary tuberculosis is superior to the acid-fast staining smear of lavage fluid and the mycobacterium culture method.
\end{abstract}

Corresponding author: Xian-Gao Jiang, Department of Infectious Diseases, Wenzhou Central Hospital, Wenzhou, Zhejiang, China, Tel: +86 13676788085. E-mail:jiang_xiangao@126.com 


\section{Valor de GeneXpert MTB / RIF en liquido de lavado broncoalveolar en el diagnóstico de tuberculosis pulmonar con frotis negativo}

Invest Clin 2021; 62 (1): 28-36

Palabras clave: líquido de lavado broncoalveolar; Xpert MTB / RIF; tuberculosis; cultivo de Mycobacterium; resistencia a la rifampicina.

Resumen. Este estudio tiene como objetivo evaluar el valor de Xpert MTB / RIF en líquido de lavado broncoalveolar (BALF) en el diaǵnóstico de tuberculosis pulmonar con frotis negativo. Se reclutaron 197 pacientes con sospecha de tuberculosis pulmonar desde enero de 2019 hasta diciembre de 2019 y se recogió líquido de lavado broncoalveolar para frotis de tinción acido-resistente, cultivo en medio líquido de sensibilidad a fármacos combinados de Mycobacterium y detección de Xpert MTB/RIF. Se calcularon la sensibilidad, especificidad, valor predictivo positivo y valor predictivo negativo de Xpert MTB/RIF en el líquido de lavado broncoalveolar (BALF), con tuberculosis pulmonar con frotis negativo como estándar de referencia. La consistencia de Xpert MTB/RIF en el diagnóstico de resistencia a la rifampicina se evaluó con los resultados de la prueba de sensibilidad al fármaco en cultivo en medio líquido de Mycobacterium y la prueba de sensibilidad al fármaco como patrón oro. Los resultados mostraron que entre 197 pacientes sospechosos de tuberculosis, 55 no fueron diagnosticados con tuberculosis y 142 fueron diagnosticados con tuberculosis pulmonar con frotis negativo; 123 casos $(86,62 \%)$ fueron positivos para Xpert MTB / RIF en el líquido de lavado broncoalveolar, 15 casos (10,56\%) fueron positivos por el método de frotis de tinción ácido-resistente y 88 casos $(61,97 \%)$ fueron positivos por el método de cultivo en medio líquido. La tasa positiva de Xpert MTB/RIF fue del 93,18\% (82/88), que fue superior a la del 75,93\% $(41 / 54)$ del cultivo de micobacterias BALF negativo $(\chi 2=8,598, \mathrm{P}<0,01)$. La sensibilidad y especificidad de Xpert MTB / RIF para la resistencia a la rifampicina fueron $100,00 \%$ y $97,30 \%$, respectivamente. Por lo tanto, el valor de Xpert MTB/RIF en el líquido de lavado broncoalveolar en el diagnóstico de la tuberculosis pulmonar con frotis negativo, es superior al frotis de tinción acidoresistente del líquido de lavado y al método de cultivo de micobacterias.

Received: 14-08-2020 Accepted: 04-01-2021

\section{INTRODUCTION}

The World Health Organization (WHO) reported that more than six million people contracted tuberculosis in 2018 (1). At present, China continues to be one of the highest TB burden countries in the world. In recent years, the prevalence rate of active pulmo- nary tuberculosis in China has decreased slowly (2), with smear-negative tuberculosis patients accounting for about 70\% of active pulmonary tuberculosis patients. Thus, smear-negative tuberculosis patients are a group that can hardly be ignored. The diagnosis of tuberculosis mainly relies on the acid-fast staining of sputum smear, albeit with

Vol. 62(1): 28 - 36, 2021 
low sensitivity. The sensitivity of positive Mycobacterium tuberculosis (MTB) culture specimens is only $44 \%-80 \%(3,4)$, which makes it easy to miss. Fiber optic bronchoscopy is an important auxiliary examination and diagnosis method for smear-negative pulmonary tuberculosis (5). It can improve the disease diagnosis by collecting specimens through bronchoscopy, brush biopsy, bronchoalveolar lavage fluid (BALF), biopsy and other methods.

Xpert MTB/RIF designs primers and probes for the rifampicin resistance determination region in the rpoB gene and $81 \mathrm{bp}$ gene of MTB to detect the presence of a mutation. It is also used to determine whether the patient had TB disease (6-8). Since most rifampicin-resistant strains are resistant to isoniazid, the resistance to rifampicin can be used as a monitoring indicator of suspected MDR-TB to a certain extent [9]. Numerous studies have found that this method has high sensitivity and specificity in detecting MTB by sputum samples (9-11), although the collection and results of sputum samples are affected by many factors. Using BALF as specimen not only solves the problem of no sputum, but it also comes directly from the segmental bronchus where the lesion is located. The bacterial content is relatively high, and the positive rate of detection is significantly improved. It can achieve the rapid early diagnosis of smear-negative pulmonary tuberculosis, which is of great significance for the early and rapid diagnosis of tuberculosis.

This study reports the value of Xpert MTB/RIF applied to BALF in the diagnosis of smear-negative pulmonary tuberculosis.

\section{MATERIAL AND METHODS}

Fiber optic bronchoscopy was performed on 197 suspected pulmonary tuberculosis patients admitted to Wenzhou Central Hospital (Nanbaixiang District) from January 2019 to December 2019. The diagnostic criteria for tuberculosis adhered to the Chinese
Pulmonary Diagnosis Criteria WS288-2017 (12) (Mycobacterium tuberculosis was detected in bronchial etiology). This study was approved by the medical ethics committee of our hospital (approval number: L2020-01001). The laboratory procedures were under external quality control programs.

Inclusion criteria: (1) clinical manifestations of pulmonary tuberculosis (e.g. cough, expectoration, hemoptysis and fever) and/or chest imaging manifestations (e.g. pneumonia and cavity); (2) three negative sputum acid-fast staining smears; (3) patients' informed consent; (4) subjects older than 14 years of age; (5) there was no gender limitation.

Exclusion criteria: (1) patients with contraindications to fiber optic bronchoscopy; (2) patients with cancer; (3) patients whose clinical data was incomplete.

\section{Fiber bronchoscope BALF collection}

Under the nasal eatheter for oxygen inhalation, ECG, respiration and blood oxygen saturation monitoring, $80 \mathrm{~mL}$ of sterile saline solution $\left(37^{\circ} \mathrm{C}\right)$ were infused twice into bronchoalveolar through the Olympus BF-1TQ170 fibre bronchoscope using a disposable lavage device; it was then recovered with negative pressure. The negative pressure was $40-60 \mathrm{mmHg}(1 \mathrm{mmHg}=1.333$ $\mathrm{kPa})$, and the recovery rate was more than $40 \%$ for a successful recovery. Each patient's BALF was divided evenly into three parts and sent immediately for examination.

\section{Acid-fast staining smear method}

Five $\mathrm{mL}$ of BALF were added to a $10-\mathrm{mL}$ disposable sterile test tube, and centrifuged at $3000 \times \mathrm{g}$ for $10 \mathrm{~min}$. Then, the supernatant was gently aspirates and discarded it. Next, the bottom sediment was taken for smear, with the coating area being $10 \times 20$ $\mathrm{mm}$ and dried at a constant temperature using a drying machine. Afterwards, a carbolic acid red dyeing solution was added, followed by a 10 min-decolorization with $3 \%$ of hydrochloric acid, alcohol for $1 \mathrm{~min}$, 
and then re-died with methylene blue for 30 s. Subsequently, washed and dried and then immersion oil was added on it. A binocular microscope with a $10 \times$-eyepiece and a $100 \times$-objective was used for observation. It was considered positive if more than one acid-fast bacillus was detected per 300 fields examined.

\section{BACTEC MGIT 960 mycobacterium cul- ture method}

The Bectec MGIT 960 system has been proved capable of measuring the sensitivity of second-line drugs. It is a fully automatic, radiation-free and non-invasive system for the identification and drug sensitivity of mycobacteria $(13,14)$. In this study, after BALF was fully mixed, $5 \mathrm{~mL}$ were added to a 50 $\mathrm{mL}$ disposable centrifuge tube. The volume of NALC-NaOH employed for culture was the same as the BALF volume. After $15 \mathrm{~min}$, phosphate was added to $45 \mathrm{~mL}$ for mixing. Then, centrifuged at $3000 \mathrm{~g}$ for $15 \mathrm{~min}$. the supernatant was discarded, and then a small amount of phosphate was added for resuspension. After that, $0.5 \mathrm{~mL}$ of suspension was added to the MGIT tube for culture. The positive culture tube was confirmed by acidfast staining, and the bacteria type of the acid-fast staining positive culture medium was identified. After the identification, if the result was MTB, the drug sensitivity test was carried out according to Modern Tuberculosis Diagnosis Technology.

\section{Xpert MTB/RIF detection}

The digestion solution was added to BALF to obtain attain a ratio of digestion liquid and BALF of 1:1 (V/V). The cover of the test tube was tightened and oscillated with a vortex oscillator for $30 \mathrm{~s}$. the mixture was placed at room temperature for $15 \mathrm{~min}$ until there was no visible granular substance in the mixture. Then, $2 \mathrm{~mL}$ of the mixture was added to the cartridge, and then the cartridge inserted into the Gene Xpert instrument for automatic detection. The system automatically displayed the test results after about two hours. The method employed to identify M. tuberculosis from culture positive tubes was an etiological culture. In this study, we employed a composite reference standard that combined bacteriological and clinical results. Additionally, we analyzed the results using the culture results as reference standard.

\section{Statistical methods}

SPSS 17.0 software for the statistical analysis of data was used. The count data were expressed by rate, and the comparison was performed by the $\chi^{2}$ test. The difference of $p<0.05$ was considered statistically significant.

\section{RESULTS}

\section{Clinical data}

Among the 197 suspected tuberculosis patients, 55 patients were not diagnosed with tuberculosis, and 142 patients were diagnosed with smear-negative pulmonary tuberculosis, including 95 males and 47 females, aged from 15 to 82-years old, with an average age of $37.54 \pm 15.11$. Among them, 129 eases were positive for etiological evidence (BALF acid-fast staining smears, Xpert MTB/RIF, mycobacterial culture). Xpert diagnosed 13 MTB cases that were not diagnosed by other methods and 55 cases were non-tuberculosis respiratory diseases, including 33 males and 22 females, aged 17-67 years, with an average of 46.33 \pm 13.11 years old. Of these 55 cases , 35 had pneumonia, six cases had a chronic obstructive pulmonary disease, six cases had bronchiectasis with hemoptysis, four cases had lung cancer, three cases had an atypical mycobacterial lung disease, and one case had a pulmonary fungal disease. There were no significant differences in age and gender between the two groups $(p>0.05)$.

In smear-negative pulmonary tuberculosis patients, 123 cases were positive for BALF Xpert MTB/RIF, 15 cases were positive in BALF acid-fast staining smear, and 88 cas-

Vol. 62(1): 28 - 36, 2021 
es were positive in the BALF mycobacterium culture. Among the patients with non-tuberculosis respiratory diseases, the BALF of three patients was cultured with nontuberculous mycobacteria. BALF acid-fast staining was negative in BALF Xpert.

\section{Comparison of three detection methods considering smear-negative pulmonary tuberculosis as the standard}

The sensitivity, specificity, positive and negative predictive values of BALF Xpert MTB/RIF, BALF acid-fast staining smear and the BALF mycobacterium culture were $86.62 \%, 100.00 \%, 100.00 \%, 74.32 \%$, $10.56 \%, 94.55 \%, 83.33 \%, 29.05 \%, 61.97 \%$, $94.55 \%, 96.70 \%$ and $49.06 \%$, respectively (see Table I). The ROC curve analysis showed that Xpert MTB/RIF and smear and mycobacterium culture areas were $0.933,0.526$ and 0.783 , respectively. The accuracy of BALF Xpert MTB/RIF was higher than that of BALF acid-fast staining smear and BALF mycobacterium culture (Fig. 1).

\section{The value of Xpert MTB/RIF using BALF} in the diagnosis of smear-negative pulmonary tuberculosis

The positive result of the BALF culture was used as the gold standard for diagnosis. Among the positive BALF mycobacterial cultures, 82 cases were positive, and six cases were negative in Xpert MTB/RIF. Among the negative BALF mycobacterial culture, 41 cases were positive, and 13 eases were negative in Xpert $\mathrm{MTB} / \mathrm{RIF}$. The positive detection rate of BALF Xpert MTB/RIF was 93.18\% (82/88), which was higher than $75.93 \%(41 / 54)$ of the negative BALF mycobacterium culture. The chi-square test was performed on BALF Xpert MTB/RIF and the BALF phenotypic drug susceptibility testing, $\chi^{2}=8.598, p<0.01$. The results were statistically significant by these two kinds of detection methods.

TABLE I

COMPARISON OF THREE DETECTION METHODS IN THE DIAGNOSIS OF SMEAR NEGATIVE PULMONARY TUBERCULOSIS BY BALF.

\begin{tabular}{lcccccc}
\hline \multirow{2}{*}{ Test method } & \multicolumn{2}{c}{ Xpert MTB/RIF } & \multicolumn{2}{c}{ Lavage fluid smear } & \multicolumn{2}{c}{$\begin{array}{c}\text { Tuberculous culture } \\
\text { in lavage fluid }\end{array}$} \\
\cline { 2 - 6 } & $\begin{array}{c}\text { Pulmonary } \\
\text { Tuberculosis }\end{array}$ & $\begin{array}{c}\text { Non } \\
\text { tuberculosis }\end{array}$ & $\begin{array}{c}\text { Pulmonary } \\
\text { Tuberculosis }\end{array}$ & $\begin{array}{c}\text { Non } \\
\text { tuberculosis }\end{array}$ & $\begin{array}{c}\text { Pulmonary } \\
\text { Tuberculosis }\end{array}$ & $\begin{array}{c}\text { Non } \\
\text { tuberculosis }\end{array}$ \\
\hline Positive & 123 & 0 & 15 & 3 & 88 & 3 \\
Negative & 19 & 55 & 127 & 52 & 54 & 52 \\
Total & 142 & 55 & 142 & 55 & 142 & 55 \\
& & & & & 61.97 \\
Sensitivity (\%) & 86.62 & 10.56 & $(88 / 142)$ \\
& $(123 / 142)$ & $(15 / 142)$ & 94.55 \\
Specificity (\%) & 100.00 & 94.55 & $(52 / 55)$ \\
Positive predictive & $(55 / 55)$ & $(52 / 55)$ & 96.70 \\
value (\%) & 100.00 & 83.33 & $(88 / 91)$ \\
Negative & $(123 / 123)$ & $(15 / 18)$ & 49.06 \\
predictive & 74.32 & 29.05 & $(52 / 106)$ \\
value (\%) & $(55 / 74)$ & $(52 / 179)$ & & \\
\end{tabular}




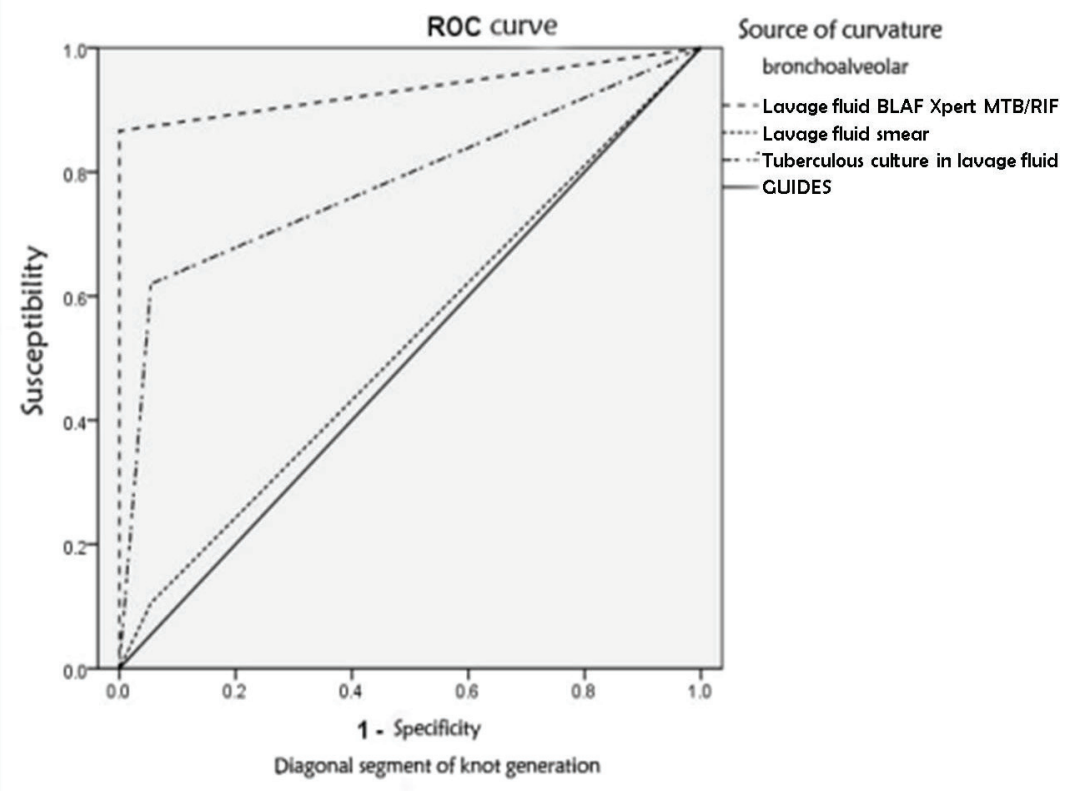

Fig. 1. Curves of three detection methods (BALF Xpert MTB/RIF, BALF acid-fast staining smear, BALF mycobacterium culture).

\section{Rifampicin resistance analysis in BALF Xpert MTB/RIF detection}

Among 82 positive cultures, Xpert were 10 resistant and 72 sensitive. Taking the drug susceptibility test after the positive BALF mycobacteria culture as the gold standard, the sensitivity and specificity of Xpert MTB/RIF were $8 / 8$ and $72 / 74$, respectively.

\section{DISCUSSION}

Tuberculosis is still a global public health problem endangering human health, with China suffering the most. Early diagnosis and treatment are key to improving the prognosis of tuberculosis patients and also, controlling the spread of tuberculosis. At present, many tuberculosis patients do not have specific clinical manifestations, and they lack typical imaging features. Efficient and rapid diagnosis of patients with early infection plays a key role in controlling the spread of the tuberculosis epidemic. According to the traditional sputum search for acid-fast bacilli and MTB culture methods, the detection rate is low and time-consuming. It is very difficult to make a clear diagnosis of clinical patients with little or no sputum. Detection under bronchoscopy can hardly reveal the scope of the disease. In addition, alveolar lavage can more effectively collect specimens, thereby increasing the diagnostic rate. The Xpert MTB/RIF assay fully integrates the three main steps (nucleic acid extraction, amplification and detection) required for the traditional nucleic acid amplification detection. After the pre-processed sample is put into the cartridge, the system will automatically proceed with nucleic acid extraction, nucleic acid amplification and product detection. Then, the results will be automatically given after the reaction is over. The whole method is straightforward and convenient; it requires low experimental conditions, and it is suitable for primary hospitals.

Since the publication of the first report on Xpert MTB/RIF in 2010 (15), countries with a high (16-18) and low (19) rate of tuberculosis worldwide have carried out 
confirmatory evaluations of this method. The results show that the sensitivity of Xpert MTB/RIF is $76.9 \%-100.0 \%$, although the sensitivity of the sputum Xpert MTB/ RIF test for the diagnosis of smear-negative tuberculosis is only $48.6 \%-77.7 \%(20,21)$. This study showed that the sensitivity, specificity, and positive and negative predictive values of BALF Xpert MTB/RIF in the diagnosis of smear-negative pulmonary tuberculosis are $86.62 \%, 100.00 \%, 100.00 \%$ and $74.32 \%$, which are similar to those reported by Gao Chunjing et al. (22). The ROC curve analysis of these three detection methods showed that the accuracy of BALF Xpert MTB/RIF is higher than that of BALF acidfast staining smear and the BALF mycobacterium culture.

According to the recommendation of WHO, Xpert MTB/RIF was used as a preliminary screening and diagnostic test for suspected MDR-TB or HIV-related tubereulosis among adults (23). The results showed that the sensitivity and specificity of Xpert MTB/ RIF for rifampicin resistance are $100.00 \%$ $(8 / 8)$ and $97.30 \%(72 / 74)$, respectively, which are consistent with the previous reports indicating that the sensitivity and speeificity of Xpert MTB/RIF for rifampicin resistance are $92.9 \%-100.0 \%$ and $98.6 \%-100.0 \%$ (24-27), respectively. This study found that two samples were rifampicin resistant in BALF Xpert MTB/RIF, while they were sensitive on the phenotypic drug sensitivity test. The false resistance on Xpert MTB/RIF may be related to the silent mutation or misinterpretation of the Xpert MTB/RIF detection system $(28,29)$.

Recently, the prevalence rate of active pulmonary tuberculosis in China has decreased slowly, with smear-negative tuberculosis patients accounting for about $70 \%$ of active pulmonary tuberculosis patients. Thus, smear-negative tuberculosis patients are a group that can hardly be ignored. Meng et al. (24) conducted a meta-analysis and found that Xpert Ultra exhibits a viable alternative in sensitivities in both pulmonary TB and extrapulmonary $\mathrm{TB}$, which was proved to be higher than Xpert in the comparative analysis, and shows a good performance in the detection of RIF's resistance. This study evaluates the value of Xpert MTB/RIF applied to BALF in the diagnosis of smear-negative pulmonary tuberculosis. However, we did not conduct an ROC curve about the comparison of the three detection methods considering smear-negative pulmonary tuberculosis as the standard in this study, which should be further investigated in the future. Although the commercial molecular test, evaluated in this study was first recommended by WHO in 2010, this study had provided confirmatory evidence on the value of the assay to detect TB and rifampin resistant TB by using BALF clinical specimens.

Limitations. Firstly, two RIF-R resistant strains by X-Pert/MTB/RIF and sensitive by the phenotypic method used, still need further investigation. Secondly, as a preliminary study, we did not detected the additional yield of the Xpert over culture, which should be object of further research.

To sum up, Xpert MTB/RIF is a simple, rapid and accurate detection method. The BALF Xpert MTB/RIF detection has high specificity and sensitivity in the diagnosis of smear-negative pulmonary tuberculosis, and its sensitivity is significantly higher than that of BALF acid-fast bacillus and the BALF mycobacterium culture method. Moreover, detection is fast and can determine the presence of rifampicin resistance. With the popularity of bronchoscopy, BALF Xpert MTB/ RIF has a good application value in the rapid diagnosis of smear-negative pulmonary tuberculosis.

\section{ACKNOWLEDGMENTS}

This work was founded by Zhejiang Basic Public Welfare Research Project (LGF18H010003) and Wenzhou Science and Technology Bureau Project (Y20180599). 


\section{REFERENCES}

1. Van Deun A, Decroo T, Tahseen S, Trébucq A, Chiang C-Y. World Health Organization 2018 treatment guidelines for rifampicinresistant tuberculosis: uncertainty, potential risks and the way forward. Int J Antimicrob Agents 2020; 55(1):105822.

2. Wang L, Zhang H, Ruan Y. Tuberculosis prevalence in China, 1990-2010; a longitudinal analysis of national survey data. Lancet $2014 ; 383$ (9934): 2057-2064.

3. Williamson DA, Basu I, Bower J. An evaluation of the Xpert MTB/RIF assay and detection of false-positive rifampicin resistance in Mycobacterium tuberculosis. Diagn Microbiol Infect Dis 2012; 74(2):207-209.

4. Park SW, Klotzsche M, Wilson DJ, Boshoff HI, Eoh H, Manjunatha U, Blumenthal A, Rhee K, Barry CE, Aldrich CC. Evaluating the sensitivity of Mycobacterium tuberculosis to biotin dprivation using regulated gene expression. Plos Pathogens 2011; $7(9)$ :e1002264.

5. Lu NH, Yang S, Li L. Clinical significance of fiberoptic bronchoscopy in the diagnosis of pulmonary tuberculosis . J Clin Slep Med 2015; 20(2): 207-209.

6. Vanna-Basil M, El Hajj H, Colangeli R. Rapid detection of rifampin resistance in Mycobacterium tuberculosis isolates from India and Mexico by a molecular beacon assay. J Clin Microbio1 2004; 42(12):5512 5516.

7. Blakemore R, Story E, Helb D, Kop J, Banada $\mathrm{P}$, Owens MR, Chakravorty $\mathrm{S}$, Jones M, Alland D. Evaluation of the anaytical performance of the Xpert Mtb/IF assay. J Clin Micro Biol 2010; 48(7):2495 2501.

8. Boehme CG, Nabeta P, Hillemann D. Rapid molecular detection of tuberculosis and rifampin resistance. N Enǵ1 J Med 2010; 363(11):1005-1015.

9. Canan Gürsoy N, Yakupoullar Y, Tekerekolu MS, Otlu B. Evaluation of the diagnostic performance of Xpert MTB/RIF test for the detection of Mycobacterium tuberculosis and rifampin resistance in clinical samples. Mikrobiyol Bul 2016; 50(2):196-204.

10. Zhang GQ, Ju HF, Zhong D. Analysis of the diagnostic effect of Xpert MTB/RIF in patients with suspected pulmonary tuberculo- sis. Chinese Tropical Medicine 2017; 17 (3): 266-269.

11. Liu JQ, Zhang LX, Qin ZH. Xpert MTB/ RIF and t SPOT.TB Evaluation of diagnostic value of smear negative pulmonary tuberculosis . J Clin Lab 2016; 34(10):755-757.

12. National Health and Family Planning Commission of the people's Republic of China. Diagnostic criteria for tubereulosis (WS 288-2017)[J]. Emerg Infect Dis 2018; 3(1):59-61.

13. Hongler $\mathbf{J}$, Musaazi $\mathbf{J}$, Ledergerber $\mathrm{B}$, Eberhard N, Castelnuovo B. Comparison of Lwenstein-Jensen and BACTEC MGIT 960 culture for Mycobacterium tuberculosis in people living with HIV. HIV Medicine 2018; 19(9):654-661.

14. Sivaramakrishnan G, Subramanyam B, Prem Kumar M, Golla R, Mondal R. Validation of bedaquiline drug-susceptibility testing by BACTEC MGIT 960 system for Mycobacterium tuberculosis. Int J Mycobacteriol 2019; 8(4):329-332.

15. World Health Organization. Who approves new rapid detection method for tuberculosis [EB/OL],(2010-12-08) [201507-20].http://www.who.int/mediacentre/ news/releases/2010/tb_test_20101208/ zh/.World Health Organization.WHO endorses new rapid tuberculosis test[EB/ OL], (2010-12-08) [2015-07-20]. http:// www. who.int/ mediacentre/news/releases/2010/tb_test_20101208/zh/.

16. Myneedu VP, Behera D, Verma AK. Xpert MTB/RIF assay for tuberculosis diagnosis:evaluation in an Indian setting. Int J Tubere Lung Dis 2014; 18(8):958-960.

17. Ou X, Xia H, Li Q, Pang Y, Wang S, Zhao B, Song Y, Zhou Y, Zheng Y, Zhang Z, Zhang Z, Li J, Dong H, Chi J, Zhang J, Kam KM, Huan S, Jun Y, Chin DP, Zhao Y. A feasibility study of the Xpert MTB/RIF test at the peripheral level laboratory in China. Int $\mathrm{J}$ Infect Dis 2015;31:41-46.

18. Kurbatova EV, Kaminski DA, ErokhinV. Performance of Cepheid ${ }^{\circledR}$ Xpert MTB/ RIF® and TB-Biochip ${ }^{\circledR}$ MDR in two regions of Russia with a high prevalence of drugresistant tuberculosis. Eur J Clin Microbiol Infect Dis 2013; 32(6):735-743.

19. Mokaddas E, Ahmad S, Eldeen HS, Al-Mutairi N, Carroll KC. Discordance between

Vol. 62(1): 28 - 36, 2021 
Xpert MTB/RIF assay and Bactec MGIT 960 culture system for detection of rifampin-resistant Mycobacterium tuberculosis isolates in a country with a low tuberculosis (TB) incidence. J Clin Microbiol 2015;53(4):13511354.

20. Sharma SK, Kohli M, Yadav RN. Evaluating the diagnostic accuracy of Xpert MTB/RIF assay in pulmonary tuberculosis. PLoS One 2015;10(10): e0141011.

21. Geleta DA, Megerssa YC, Gudeta AN. Xpert MTB/RIF assay for diagnosis of pulmonary tuberculosis in sputum specimens in remote health care facility. BMC Microbiol 2015;15:220.

22. Gao JC, Zhu SY. Diagnostic value of xpert MTB/RIF in bronchoalveolar lavage fluid for smear negative pulmonary tuberculosis. J Clin Sleep Med 2016; 21(12):2192-2196.

23. Haraka F, Schumacher SG, Ross A, Mantsoki A, Gagneux S, Reither K, Denkinger CM. Effect of history of tuberculosis on specificity of Xpert MTB/RIF. Eur Respir J 2020:56 (3):2000343.

24. Boehme CC, Nicol M P, Nabeta P. Feasibility, diagnostic accuracy, and effectiveness of descentralized use of the Xpert M TB/RIF test for diagnosis of tuberculosis and multidrug resistance: a multicentre implementa- tion study. Lancet, 2011; $377(9776)$ :14951505.

25. Hu P, Bai L, Liu F. Evaluation of the Xpert $\mathrm{M} \mathrm{TB} / \mathrm{RIF}$ assay for diagnosis of tubereulosis and rifampin resistance in county level laboratories in Hunan provinee, China. Chin Med (Engl) 2014;127(21):3744-3750.

26. He GQ, Li T, Shi JC. Evaluation of elinical application of rifampicin resistant $\mathrm{Myco}$ bacterium tuberculosis in 214 patients with pulmonary tuberculosis. Chinese $\mathrm{J}$ Infect Dis 2016; 34(6):349-353.

27. Zhao JY, Jin FX, Xu WF, Xu P, Xue QL. Rapid detection of multidrug resistant MTB and Xpert MTB/RIF by gene B. Chinese J Nosocomial Infect 2017; 27(19):43404343.

28. Marlowe EM, Novak-Weekley SM, Cumpio J. Evaluation of the Cepheid Xpert MTB/RIF assay for direct detection of Mycobacterium tuberculosis complex in respiratory specimens. J Clin Microbiol 2011;49(4):16211623.

29. Mathys V, van de Vyvere $M$, de Droogh E, Soetaert K, Groenen G. False- positive rifampicin resistance on Xpert MTB/RIF caused by a silent mutation in the rpoB gene. Int J T ubere Lung Dis 2014;18(10):12551257. 